\section{ECONOMICS}

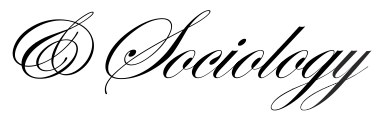

\title{
PERCEPTION OF THE SOCIAL STATUS OF INTELLIGENCE IN SELECTED COUNTRIES OF THE FORMER YUGOSLAVIA
}

\author{
Veselin Draskovic, \\ University of Social Sciences, \\ Poland, \\ University of Montenegro, \\ Montenegro \\ E-mail:veso-mimo@t-com.me \\ ORCID 0000-0003-3968-422X \\ Svitlana Bilan, \\ Rzeszón University of Technology, \\ Poland, \\ E-mail:s.bilan@prz.edu.pl \\ ORCID 0000-0001-9814-5459
}

Received: December, 2018

1st Revision: March, 2019

Accepted: May, 2019

DOI: $10.14254 / 2071-$

789X.2019/12-2/19

JEL Classification: A13, Z13
ABSTRACT. The subject of this paper is a comparative analysis of the social status of intelligence in three selected countries of the former Yugoslavia: Bosnia and Herzegovina (B\&H), Montenegro (MNE), and Serbia (SER). The aim of this research is the perception of the impact of certain selected factors on the social status of inteligence in these countries. It starts with the hypothesis that the social status of intelligence in the post-socialist transition process has been permanently deteriorated, mainly due to the unfavorable and synergistic impact of political, economic, institutional, and cultural-educational factors. In this paper, survey method and multiple linear regression method were used to determine the hypothetical perceptions of intellectuals on the social status of intelligence and an impact of basic social factors on it. It was concluded that the hypothesis has been verified and that the respondents in the observed countries in large percentage and sufficiently homogeneously have estimated that the position of intelligence was objectively deteriorating during the observation period.

Keywords: intelligence, social status of intelligence, Bosnia and Herzegovina, Montenegro, Serbia.

\section{Introduction}

In researching social, economic, political, and other transition problems, which make the essence of a permanent crisis, most post-socialist authors avoid to examine an evident and significant social phenomenon. It is the permanent and long-term deterioration of the social status of intelligence in the countries of former Yugoslavia. During the three decades of postsocialist transition, many factors had a negative complementary impact on the state of intelligence, and many factors were exposed to negative and complementary impacts. This paper selected them for the purpose of political, economic, institutional, and cultural survey (Yerznkyan et al., 2017; Wróblewski et al., 2018). The process of general liberalization contributed to the creation of various destructive and non-functional social structures 
(political, economic, organizational, institutional, and normative - V. Draskovic and M. Draskovic, 2012). General social and economic insecurity has increased. The system of social values has changed dramatically, with an obvious fall in the criterion. All this directly caused the deterioration of the (socialist) relatively good social status of intelligence.

The non-economic factors were dominantly negatively impacted by political-party factors. Various (politically imposed) reforms have caused a decline in the quality of education, especially higher education (Fotea \& Guțu, 2016). This has further directly caused a long-term high unemployment rate among academic staff. In addition, there has been an increase in the deficit of democratic institutions and the rule of law, a value criteria crisis, and a sophisticated combination of monopolism and dogmatism in society. All this consequently induced the negative selection of staff, the so-called "political employment", the reduction of social and economic choices, various forms of social pathology, opportunistic behavior and institutional violence towards society (according to D. North et al, 2009), etc. Logically, these phenomena have limited the activities of intelligentsia in the observed countries (in scientific institutions, professional associations, and other organizational forms) to a lesser or greater extent.

The introduction of a new mercantilistic and pseudo-neoliberal value system, and new forms of a party's "monopoly on the truth" (Delibasic, 2016, p. 149; Draskovic, 2015, p. 97) has allowed the dominance of the interests of privileged individuals and narrow social, political and economic groups (conditionally "elite"). They initiated and implemented the rapacious distribution of national resources. In this process, which in many manifestations looked like the original accumulation of capital (but without the risk for the main actors), intelligentsia was significantly ignored due to its creative, and professional capacities (Ciobanu at al., 2019). It was condemned to survival. These impact factors brought intelligentsia into a crisis situation and reduced its progressive role and function as the bearer of social-cultural capital (Andrushkiv et al., 2011; Bilan et al., 2017; Delibasic, 2014, p. 15; Luchko et al., 2019; Mishchuk at al., 2017; Petrenko \& Psiuk, 2018). Different party-political (including voting) and economic mechanisms (the active and dominant role of capital, regardless of its origin), contrary to laws and other institutional rules (Götz et al., 2018), allowed to an extremely small number of privileged people to dominate, control, and manage, not only political and social processes, but also business, people, and their education (Ohanyan \& Androniceanu, 2017). That is why most intellectuals opposed the nomenclature of power and their alleged "reforms" in various ways, principally and institutionally. Unfortunatelly, these "reforms" turned into an endless process with poor results (Sulkowski, 2017).

The authorities used different methods, ideologies, myths, and rhetorics (Draskovic \& Delibasic, 2014) in terms of globalization, transition, consumerism, neoliberalism, market competition, better life, etc. Both people and intelligentsia have realized that these categories are scarce in real life. However, the dominance of quasi-intelligentsia in society was established on such apologetic slogans. By the logic of things, this affected the deterioration of the social status of intelligence, with unpredictable future consequences.

\section{Theoretical approach}

In the conducted survey, the respondents were offered the following definitions of intelligence: the enlightened social class engaged in intelligent work, whose purpose and goal is to fight for social and educational progress; bearers and creators of advanced ideas, educational and scientific values in journalism, art, literature, and science; people in three key social areas: politics (power), business, and education, possessing knowledge, truth, moral values, and aesthetic judgments (Bauman, 1989, p. 1). In this context, significant is the view 
by E. Morina (1977) who located intelligence on the basis of three main aspects: according to culturally valued profession, in accordance with its political role in society, and as a carrier of universal consciousness. In terms of socio-economic development, we think that intelligence should be viewed as the source, foundation, and propusive element of sociocultural capital (Fig. 1).

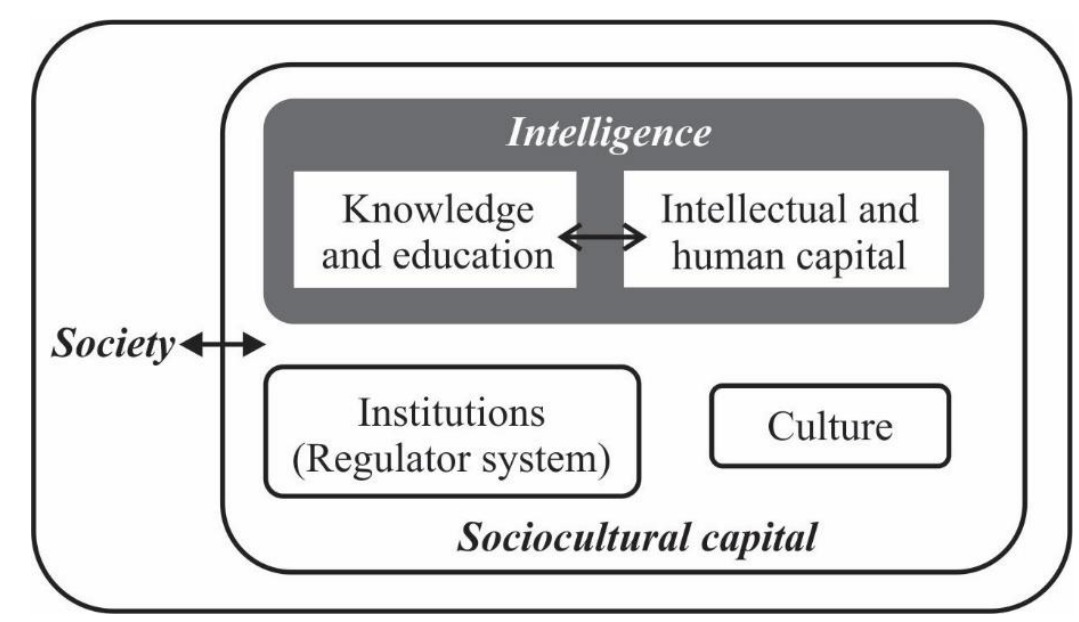

Figure 1. Intelligentsia as a part of sociocultural capital

Source: adapted from World Bank, 1999

In the three selected countries of the former Yugoslavia (B\&H, MNE, and SRB), we surveyed 100 respondents, members of intelligentsia in each country (300 in total), according to the basic criterion of their position in academic community (scientists, university and high school professors, journalists, lawyers, and other intellectuals). They were recognized for their references, advocacy for objective knowledge, free and autonomous thinking, charisma, and the like. However, we did not include two intellectual categories: neoliberals and active politicians (due to a possible impact of their apologetics on the answers).

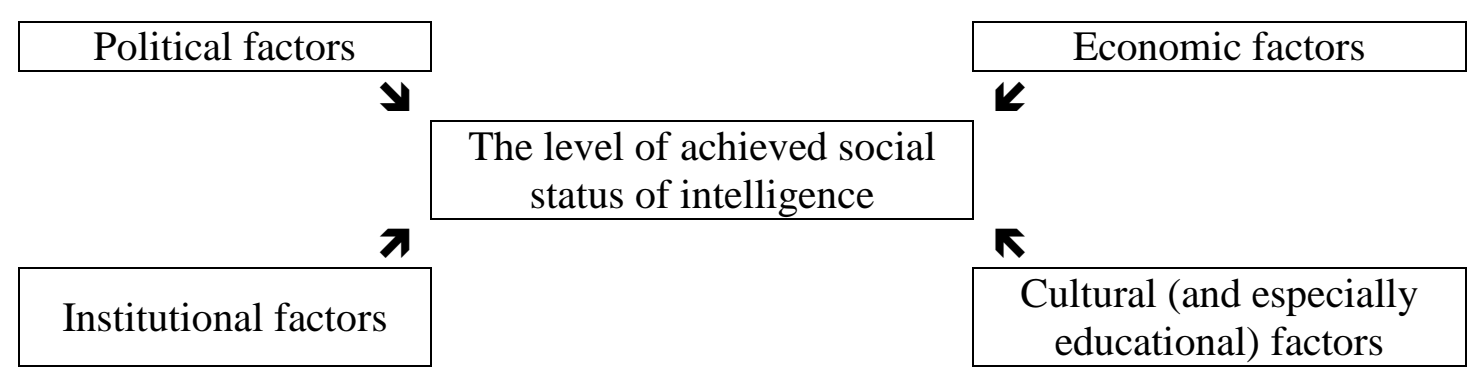

Figure 2. Research framework: modeling independent and dependent variable

Source: own modelling

Respondents from these three countries answered five questions based on their personal subjective assessment (perception). In each question, on a 9-grade scale (from 1 to 5), they assessed the dependent variable and the impact of independent variables on a dependent variable. Questions were formulated in this order:

- assess the level of achieved social status of intelligence (as a dependent variable in the hypothetical model),

- to what extent (1-5) political factors, as independent variables, negatively impacted the level of achieved social status of intelligence (as a dependent variable)? 
- to what extent (1-5) economic factors, as independent variables, negatively impacted the level of achieved social status of intelligence?

- to what extent (1-5) institutional factors, as independent variables, negatively impacted the level of achieved social intelligence?

- to what extent (1-5) cultural (and especially educational) factors, as independent variables, negatively impacted the level of achieved social status?

The schematic overview of the research framework is given in Fig. 2.

\section{Social status of intelligence in socialism and the period of "transition"}

In all selected countries of the former socialist Yugoslavia, intelligentsia actively participated in making strategic decisions on social and economic development (Androniceanu, 2019). There was a spiritual autonomy of intelligence, with an idyllically limited freedom of thought. Only few intellectuals have chosen ideologically critical (oppositional) continuity and/or dissident status. The essential characteristics of intelligentsia were: a) it was the "middle layer" that was between the working class and the governance structures, and b) it was the link between knowledge-producing institutions and authoritiesproducing institutions.

However, intelligence had certain limits, reduced to the level of making professional decisions, the level of its independence (due to priorities of the political system), the impossibility of party organization, and the inability to control despotism of the state regulation. From the historical point of view, it can be noted that the main limit of intelligence was the political engagement of its members (dependence on power), especially members of academic community, who often did not defend the reputation of intellectuals. It was the socalled "avoidance of intellectual responsibility" (Rosic, 2014, p. 98), or the so-called "betrayal of intelligence" (Benda, 1996). The reasons are the same (then and today): selfinterest, desire for power, and human cowardice.

Transition period was accompanied by a great socio-economic crisis. It has had a multiplier effect on the transformation of creative and humanistic intelligence. Under the influence of liberalization and globalization there has been a reconsideration, revaluation, and redefinition of Marxist values and dogmas. Unfortunately, one dogma (collectivism) was replaced by another - privileged individualism. Intelligentsia was increasingly losing the possibility of proper employment and reward. Therefore, its social status was objectively deteriorated and its identity was changed. The strengthening of "new elites" was followed by new forms of totalitarianism and neoliberal culture, which demonized the past and affirmed the established "quasi-neoliberalism".

Redistribution of social roles and political functions has bypassed much of intelligence, which lost its former creative identity, security, and status in society. It gained more freedom of expression, but under new conditions; it was permanently marginalized through the strengthening of social pathology, destructive pseudo-institutional monism, and inflation of educational diplomas at all levels, particularly in observed countries. This created a new transitional phenomenon of "false intelligence", which greatly increased and threatened the social status of real intelligence. Only the "life of a polytheism" was continued, because many intellectuals politically blended into "democrats", "liberals" and "reformists" (the socalled "immoral intellectuals").

Vulgarization of knowledge and its ignorance, the flood of bad master's and doctoral dissertations, professional books, and plagiarism, prove this great intellectual decline. The wrong strategy of mass higher education and its non-functional integration into the so-called "Bologna process" led to a drastic fall in the quality of teaching staff, educational courses, and knowledge of students and graduates (Poór et al., 2018; Ślusarczyk \& Herbuś, 2014). 
Therefore, a logical question arises: is this a programmed and deliberate debilisation of the people for the purpose of long-term control over it?! Many proven non-intellectuals from the ranks of politicians, party workers, policemen, and even those failing a grade in elementary school, magically acquired a doctorate and became university professors.

After that, many individuals without any scientific merits took up positions in important scientific institutions. Also, in the "criteria for the selection of scientific titles", the young cadres were set very strict criteria, which even the "criteria-makers" did not meet (nor many of the existing selected university staff). In this way, pseudo-intelligence, false intelligence and "indisputable charlatans" (a term by Tarasov, 2002) spread. They demotivated and weakened real intelligence using methods of marginalization, circumvention, and humiliation. Consequently, there has been significant immigrations of intelligence, while the process of its non-organization expanded. Especially worrying is the phenomenon of party members at the leading positions in higher, secondary, and primary education, and their percentage is approaching absolute (100\%). This relativizes all the talks on the alleged "autonomy" of faculty, university, and academic profession.

\section{The results of the survey on a position of intelligence and individual impact factors}

In order to investigate the perception of the respondents about the position of intelligence and mentioned impact factors, we conducted a survey on samples of 100 respondents in three selected countries of the former Yugoslavia (B\&H, MNE, and SER).

Mathematical model based on multiple linear regression analysis:

Social status of intelligence $(\mathrm{SSoI})=\alpha_{1} *$ political factors $+\alpha_{2} *$ economical factors $\alpha_{3} *$ institutional factors $+\alpha_{3} *$ cultural factors (particularly educational) $+\beta$.

Table 1. B\&H: Social status of intelligence statistical metrics

\begin{tabular}{cccccc}
\hline \multirow{2}{*}{ SSoI } & $\alpha_{1}$ & $\alpha_{2}$ & $\alpha_{3}$ & $\alpha_{3}$ & $\beta$ \\
\cline { 2 - 6 } & -0.044 & 0.079 & 0.103 & 0.216 & 0.124 \\
\hline Average: & MAD & MSE & MAPE & SE & r \\
\hline 1.3 & 0.399 & 0.245 & 0.410 & 0.508 & 0.234 \\
\hline
\end{tabular}

Source: Author`s estimates.

Table 2. MNE: Social status of intelligence statistical metrics

\begin{tabular}{cccccc}
\hline \multirow{2}{*}{ SSoI } & $\alpha_{1}$ & $\alpha_{2}$ & $\alpha_{3}$ & $\alpha_{4}$ & $\beta$ \\
\cline { 2 - 6 } & 0.029 & -0.064 & -0.089 & 0.242 & 1.107 \\
\hline Average: & MAD & MSE & MAPE & SE & r \\
\hline 1.6 & 0.402 & 0.277 & 0.309 & 0.540 & 0.256 \\
\hline
\end{tabular}

Source: Author`s estimates.

Table 3. SRB: Social status of intelligence statistical metrics

\begin{tabular}{cccccc}
\hline \multirow{2}{*}{ SSoI } & $\alpha_{1}$ & $\alpha_{2}$ & $\alpha_{3}$ & $\alpha_{4}$ & $\beta$ \\
\cline { 2 - 6 } & -0.109 & 0.032 & 0.020 & 0.054 & 1.364 \\
\hline Average: & MAD & MSE & MAPE & SE & r \\
\hline 1.4 & 0.409 & 0.271 & 0.431 & 0.534 & 0.156 \\
\hline
\end{tabular}

Source: Author`s estimates. 
Abbreviations in Tables above are as follows: MAD is mean absolute deviation; MSE is mean square error; MAPE is mean absolute percent error; SE is standard error of the regression estimate, while $\mathrm{r}$ is correlation coefficient. Detail descriptions on their meaning and usual interpretation can be found in (Balakrishnan et al., 2007).

In all examined cases about 40\% (MAD) of the interviewers' responds corresponds to the multiple linear regression model that gives average values in the case of $\mathrm{BaH}-1.3, \mathrm{MNE}$ - 1.6, and SRB - 1.4, respectively. In accordance to the used Lickert's scale from 1 to 5 it indicates low level of social status of intelligence in all three analyzed countries.

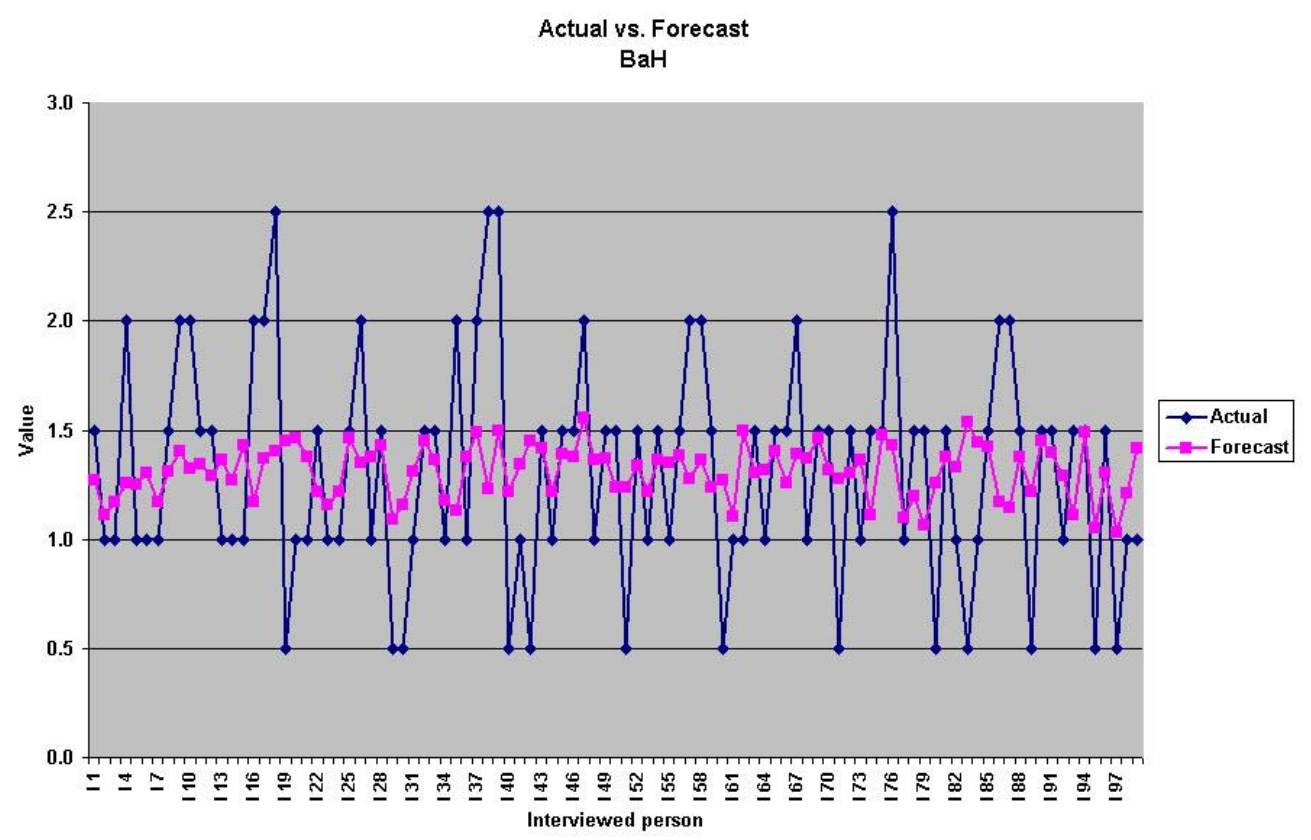

Figure 1. B\&H: Multiple linear regression model on social status of intelligence

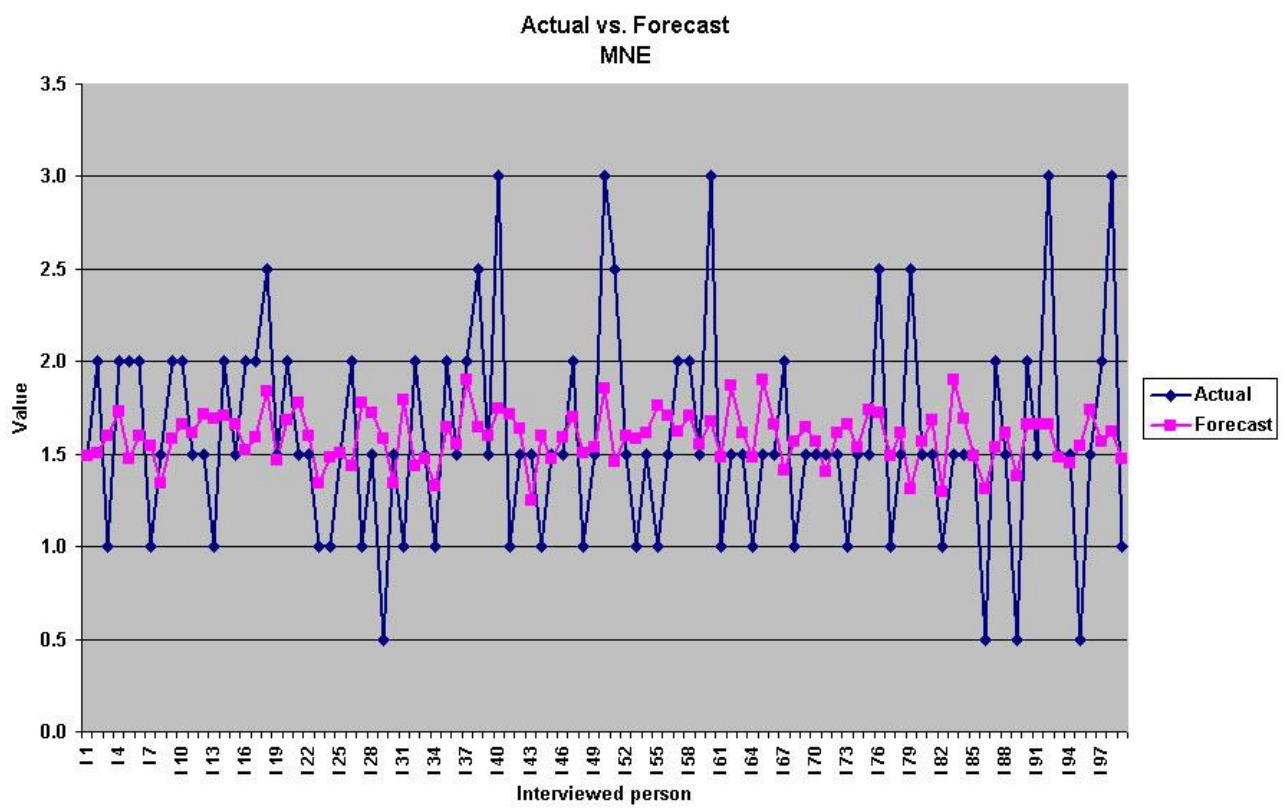

Figure 2. MNE: Multiple linear regression model on social status of intelligence 


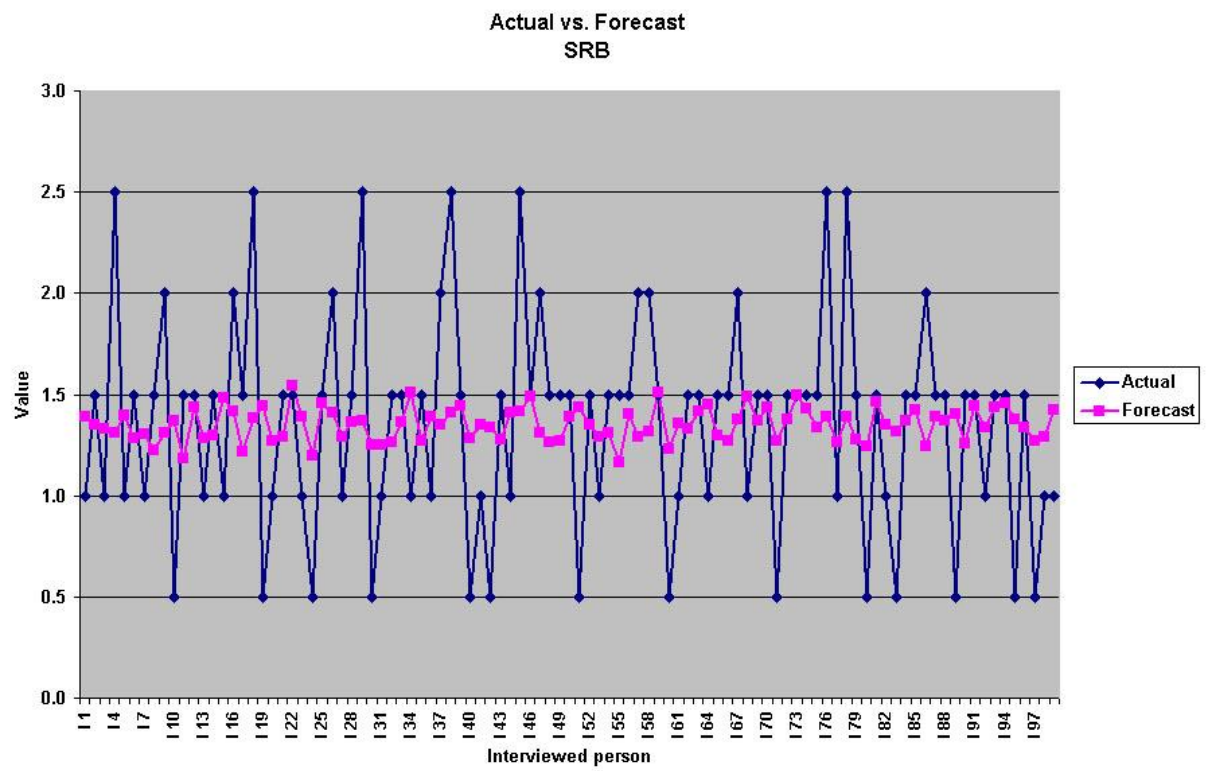

Figure 3. SRB: Multiple linear regression model on social status of intelligence

\section{Conclusion}

The domination of politics, neoliberal ideology, opportunism, and alternative institutions over social movements, knowledge, and education led to a deterioration of the socio-economic position of intelligence.

Politics consistently pushed intelligence from its universal and representative activities into segmented expert-professional activities. This significantly reduced its role in creating reforms, in spreading and increasing knowledge and spiritual values.

The obtained survey results hypothetically indicate the main conclusion that respondents in observed countries in large percentage and sufficiently homogeneously estimated that the position of intelligence in the society has objectively deteriorated during the thirty-year post-socialist transition.

Regarding the role of individual impact factors, respondents differed in each country. It was notable that in MNE respondents perceived institutional factors as dominant, while in $\mathrm{B} \& \mathrm{H}$ and SER respondents perceived political factors as dominant.

In accordance to the absolute coefficient values $\left(\alpha_{i}, i=\overline{1,4}\right)$, obtained by the model, following can be concluded: $\mathrm{BaH}$ - in the case of $\mathrm{BaH}$ the highest influence on social status of intelligence have cultural (educational) factors, than institutional, economical and political ones, respectively; MNE - again, in the case of MNE the highest influence make cultural (educational) factors, than institutional, economical and political, respectively; SRB - in the case of SRB the highest influence on social status of intelligence is caused by economical factors, than by cultural (educational), while on the third and fourth places are political and economical factors. 


\section{References}

Androniceanu, A. (2019). A managerial approach to Romania's security strategy with NATO. Journal of Security and Sustainability Issues, 8(3), 430-441. http://doi.org/10.9770/jssi.2019.8.3(11)

Andrushkiv, B., Vovk, Y., Pohaydak, O., \& Fedyshyn, I. (2011). Crisis of Relationship in General Theory of Crisis. Journal of International Studies, 4(1), 18-25.

Balakrishnan, N., Render, B., \& Stair, R.M. (2007). Managerial Decision Modeling with Spreadsheets, New Jersey: Prentice-Hall Inc.

Bauman, Z. (1989). Legislator and Interpreters: On modernity, post-modernity and intellectuals. Cambridge: Polity Press.

Benda, Z. (1996). Treason of intellectuals. Belgrade: Social thought (in Serbian).

Bilan, Y., Mishchuk, H., \& Dzhyhar, T. (2017). Human capital factors and remuneration: Analysis of relations, modelling of influence. Business: Theory and Practice, 18, 208.

Ciobanu, A, Androniceanu, A., \& Lazaroiu, G. (2019). An integrated psycho-sociological perspective on public employees' motivation and performance. Frontiers in Psychology, 10, 36. http://doi: 10.3389/fpsyg.2019.00036

Delibasic, M. (2014). The Post-socialist Transition through the Prism of O. Williamson's Insight. Montenegrin Journal of Economics, 10(1), 13-24.

Delibasic, M. (2016). Hypothetical Matrix for Institutional Modeling of the Basis for Economic Development in the Countries of Southeast Europe. Montenegrin Journal of Economics, 12(2), 147-159.

Draskovic, V. (2015). Neoliberal Totalitarianism. Theory and practice of institutional transformations in Russia. 31, 95-100.

Draskovic, V., \& Draskovic, M. (2012). Institutional Nihilism as a Basis for AntiDevelopment Policy. Montenegrin Journal of Economics. 8(1), 119-136.

Draskovic, V., \& Delibasic, M. (2014), Neoliberal Rhetoric as a Metaphor for QuasiInstitutional Monism, Montenegrin Journal of Economics, 10(2), 33-47.

Fotea, A.C., \& Guţu, C. (2016). Historical and Theoretical Framework of the Relation between Higher Education Institutions and the Process of Regional Economic Development. Entrepreneurial Business and Economics Review, 4(1), 23-42.

Götz, M., Jankowska, B., Matysek-Jędrych, A., \& Mroczek-Dąbrowska, K. (2018). Governmental change and FDI inflow to Poland and Hungary in 2010-2016. Entrepreneurial Business and Economics Review, 6(1), 153-173.

Luchko, R., Arzamasova, O., \& Vovk, I. (2019). Personnel potential of national economy and gross domestic product: The case of Ukraine. Montenegrin Journal of Economics, 15(2), 59-70. doi:10.14254/1800-5845/2019.15-2.5.

Mishchuk, H., Bilan, Y., \& Pavlushenko, L. (2016). Knowledge management systems: issues in enterprise human capital management implementation in transition economy. Polish Journal of Management Studies, 14, 163-173.

Morin, E. (1977). Intellectuals: criticism of the myth and myth of criticism. Marxism in the world, 1-2 (in Serbian).

North, D.C., Walis, J. J., \& Weingast, B. R. (2009), Violence and Social Orders - A Conceptual Framework for Interpreting Recorded Human History, Cambridge: The Syndicate of the Press.

Ohanyan G., \& Androniceanu, A. (2017). Evaluation of IMF program effects on employment in the EU. Acta Oeconomica, 67(3), 311-332.

Petrenko, V., \& Psiuk, R. (2018). Management of functionaries' development of the enterprise management system by application of the criteria experts assessment by 
method of functional reliability. Economics, Management and Sustainability, 3(1), 5864. doi:10.14254/jems.2018.3-1.5

Poór, J., Juhász, T., Machová, R., Bencsik, A., \& Bilan, S. (2018). Knowledge management in human resource management: Foreign-owned subsidiaries' practices in four CEE countries. Journal of International Studies, 11(3), 295-308. doi:10.14254/2071$8330.2018 / 11-3 / 23$

Rosic, T. (2014). Reputation on offer: intellectuals, citizens and revolutionaries. In Roksandic, D. \& Cvijović Javorina, I. (ed.), An intellectual today: Proceedings of papers from the Right Encounters 2013, Zagreb: Faculty of Philosophy, University of Zagreb, 91-106 (in Croatian).

Sulkowski L., (2017). Social Capital, Trust and Intercultural Interactions In: Rozkwitalska M., Sulkowski L., Magala S. (eds.), Intercultural Interactions in the Multicultural Workplace. Traditional and Positive Organizational Scholarship, Springer, 155-171.

Ślusarczyk, B., \& Herbuś, A. (2014). Higher education as a crucial factor of staff development. Polish Journal of Management Studies, 10(2), 216-224.

Tarasov, A.H. (2002). Revelations of the former intellectual. Free Thought. 21(2) (in Russian).

World Bank (1999). What is Social Capital? Poverty Net. (Online) Available: http://www.worldbank.org/poverty/scapital/whatsc.htm (24.01.2019).

Wróblewski, Ł., Dacko-Pikiewicz, Z., Kašík, J., \& Chytilová, L. (2018). Building the relationship between the culture organization and clients in the cross-border market. Polish Journal of Management Studies, 18(2), 402-415.

Yerznkyan, B., Gassner, L., \& Kara, A. (2017). Culture, Institutions, and Economic Performance. Montenegrin Journal of Economics, 13(2), 71-80. doi:10.14254/18005845/2017.13-2.3. 